\title{
Transition in Knitwear Design Education towards Professionalism: A Framework for Creative Knitwear Education Using Finger Knitting- Based System
}

\author{
Yao Mei Yu and Li Li* \\ Institute of Textiles and Clothing, the Hong Kong Polytechnic University, Hong Kong
}

Received: 眥 January 31, 2018; Published: 䟧 February 13, 2018

*Corresponding author: Li Li, The Hong Kong Polytechnic University, The institute of Textiles and Clothing, Hong Kong

\begin{abstract}
Due to the fast-growing knitwear markets and revival of knitting, knitwear design became important elements in design. Nevertheless, knitting was perceived as an inferior subject under current curriculum due to the deep traditional rooted role of it. Thanks to the passive learning cultures and unbalanced proportion of design and technology teaching modules, there was lack of systematic training of the knitwear design professions. This study thus aimed to develop an innovative finger knitting-based educational method to link the fundamental knowledge, realistic application and service setting of knitting. Historical development of knitting, how its impact on knitting education and the newly developed education method was discussed. Survey and informal interviews the effectiveness of this method was done. Students felt satisfied with the subject teaching method and found it useful to understand the principles of knitting.
\end{abstract}

Keywords: Finger Knitting; Knitwear Design; Knitting Technology; Service-Learning; Design Education

\section{Introduction}

Traditionally, when talking with knitting, it was usually associated with femininity, woolly stuff and old-fashion. It was even being considered as unattractive domestic craft that only elderly will perform it. It even being considered as unattractive domestic craft that only elderly will perform it. Nonetheless, knitting was undergoing resurgence that the knitting population was increasing rapidly and noticeably, 18-34 years old people is accounted for almost $20 \%$ of knitting population [1]. In the light of ubiquitous social network, like YouTube, knitting skills spread quickly and thus support its growth [2]. Also, numerous benefits were brought by knitting as supported by literatures. It also could be served as a medium of therapy [3-6]. It was even considered as a new yoga that performing it could bring the effect of claiming and relaxation [7]. Moreover, due to the refusal of consumption culture, there was a rise of "Do-It-Yourself" and "Craft Revolution" [8]. Nowadays, people appreciated hand-made products and regarded knitting as an art form. For example, Sayeg utilized colourful yarns and knitting methods to create street art that provided a warm feeling to the unforgiving city [9]. Knitwear design also became an important element in high fashion.
However, knitting was still perceived as an inconsequential subject under current curriculum due to the deep rooted role of it. Knitting was taught under home economics, which was usually overlooked and regarded as leisure-based activities. For fashion design major in university study, traditional cut-and-sewn dominated the core subjects; while for textile technology subject, the subject focused on the operation of knitting machinery instead of its principles and techniques. It was clear that insufficient and unsystematic education has been provided. This hinders the development of knitwear design and the training of knitwear profession.

Apart from this, service-learning was the prior concern of current education. This provided opportunities for students to apply their knowledge and skills acquired in university education to deal with complex issues in the service setting. Students could deepen their understanding of the academic concepts and grasped the chance to practice while build up a reciprocal relationship with the community. For future knitwear design education, knitwear profession should integrated fashion design, knitting technology and social service. Hence, this study aimed to develop an innovative finger knitting-based educational method to link the fundamental 
knowledge, realistic application and service setting of knitting. This paper was thus investigated the historical development of knitting and how its impact on knitting education. Then, the newly developed finger knitting-based system would be introduced and both survey and informal interview research on the effectiveness of this method would be discussed.

\section{Knitting Development and its Impact on Knitwear Education}

It is believed that knitting is originated in the Middle East that the first knit product was the 'Coptic socks' found in Egypt $[10,11]$. Knitting was then thrived for a long period of time that everyone, even young men, worked with it to fabricate knit products, like socks, sweaters and hats. Nevertheless, owing to the invention of knitting machines and the Industrial Revolution, knit products could be mass-produced and hand knitting became home craft that performed by housewife. Although knitting regained popularity slightly during the Great Depression and the World War, it was considered as old-fashion and rejected by young generation [11]. The revival of knitting is started from around 2000. With reference to The UK Hand Knitting Association [12], there were approximately 7.2 million of knitters in UK and there is $12 \%$ growth rate stably. Thanks to the rapid development of social network, the knitting techniques are shared swiftly. Terms related to knitting have been searched by an increasing rate of $250 \%$ a year $[2,12]$. Moreover, campaigns or projects regarding knitting are carried out to promote knitting. For example, the "Stitch 'N Pitch Night" game held in 2005 that around 1600 people joined and knitted [13]. Young people think that knitting is a creative and trendy activity now [14]. Therefore, it is doubtless that there is increasing number of people participating in knitting and shows a revival of knitting.

Knitting is also now associated with art and design, and sometimes political and social acts. There is a famous term called graffiti knitting (or yarn bombing) that, in fact, regarded as a kind of street art. A well-known example is "Knit the City" that aimed to utilize knitting and crochet with underlying subversive, feminist and political objectives. Artists cover the city by knitted pieces and tell "stitched stories" [15]. Previous research also considered knitting was associated with feminist movement [16,17]. Academic studies regarding knitting usually focus on feminist ideology rather than its benefits and development in educational aspects.

Furthermore, with the increasing popularity and world population, the market of knitwear product was growing rapidly. According to The NPD Group, Inc./Consumer Tracking Service, the total U.S. hosiery market had 3\% growth to $\$ 7.3$ billion in the past 12 months since May 2014 [18]. Population growth was a double edged sword. It brought business opportunity yet challenges to current knitwear industry. Consumers were looking for variety on styles with high quality. To survive in such highly competitive and fast-growing global market, designers and manufacturers had to improve overall versatility and creativity of their products.
This heavily replied on the profession training offered in schools. Nevertheless, current knitwear design training was far from meeting the market needs.

In the light of the prolonged historical role of knitting, knitting was regarded as domestic leisure-based activity that usually performed by housewife. The existence of systematic education on knitting can be traced back to the mid-20th century [19]. After the Second World War ended, western countries such as United States and United Kingdom, introduced the home economics curriculum consisting knitting based on the circumstances that it trained girls to meet the requirements of housewifery. This situation was even more obvious in eastern countries, where inability constitutes the virtue of women [20]. Knitting was also marginalized by current educational authorities. It was classified as an optional subject under home economics in secondary school and an elective subject under fashion design in tertiary study. The complexity and its philosophical base were neglected. Insufficient and superficial education programs and shortage of professional teachers were resulted $[19,21]$. These were not favourable for the development of the knitting industry globally.

What make the situation more badly was that the learning styles of students were relatively passive in eastern culture. Traditional Chinese learning style was influenced by Confucian values [22]. Students should not question about the knowledge of teachers and should respect the opinions of people with higher rank. Challenges to teachers were regarded as improper behaviour that might cause them to lose face. The education system required students to memorize knowledge rather than understand or criticize it. This was exemplified by the examination system, which surface learning was promoted [19,22]. Even for the technical subjects, like knitting, students were trained to memorize the steps instead of understand its principles to manipulate the skills. Therefore, students might not able to understand, create and correspond to changes. It was expected that under such an education environment, the profession was not sustainable, not to mention providing the industry with talent to cope with the challenge in the dynamic garment market.

Although some universities incorporated knitwear as an elective subject or specialism under fashion and textile design study in recent years, the focus of the subject might not be the best fit to current ever-changing world. Though people generally agreed that design should comprise of art and technology, they argued about the relative importance and the proportion on design education [23]. This resulted in imbalanced training provided. Besides, fashion design students in eastern countries were relatively weaker on science due to their learning style. Even they underwent the knitting technological training, they were usually just memorized the necessary information without real understanding in order to survive in the examination. They were hardly comprehended the principles and not able to apply it in real situation. In some situation, students were usually required to learn knitting methods 
by machinery and the knitting theory separately. This, as a result, was sadly found that students were sometimes not able to link up their works with the principles. This might further limit their design potential.

Furthermore, service-learning was become more important in current education as it brought numerous benefits, such as increasing sense of personal efficacy and awareness towards world issues $[24,25]$. It was defined as a kind of experiential education approach [26]. Experiential learning was believed to be beneficial to design education as it promoted experiencing, reflecting and thinking $[27,28]$. Knit products were usually used as gift or for charity purposes. It was a good medium for social service. This was also important for students to see their part in the larger community and learn why it is important to help others. Through community service, their learning in the classroom could be enriched and their sense of social and civic responsibility could be enhanced. These qualities were preferred, either by local or global employers. Hence, current knitwear design should incorporate art, technology and service-learning to equip students with higher competitiveness (Figure 1).

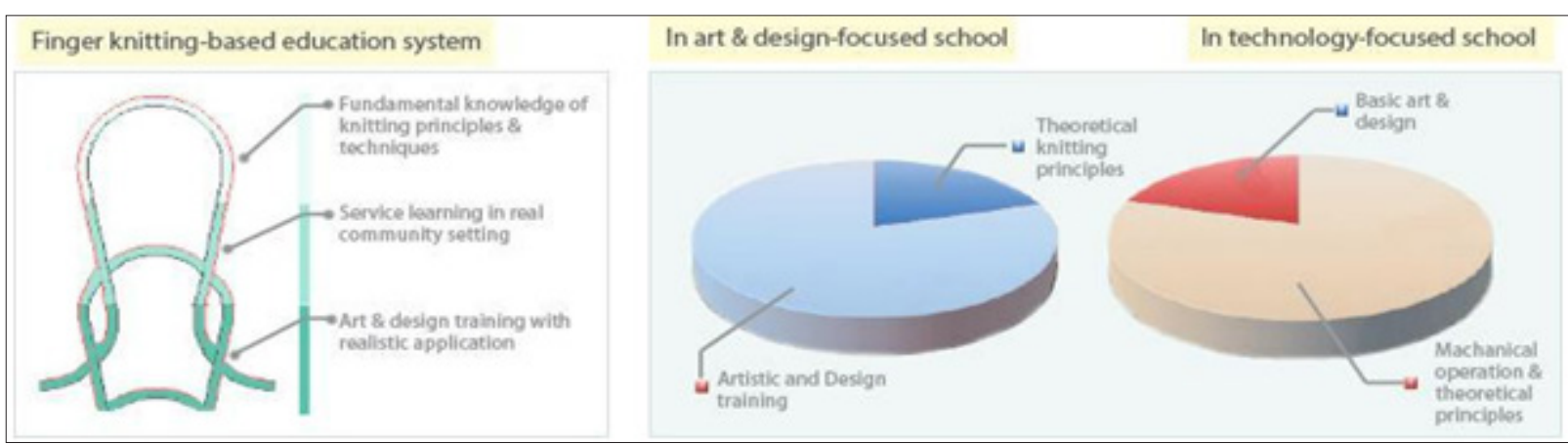

Figure 1: Illustrations showing the proportion of focuses of different knitting education system in universities.

To tackle with the current plight, this paper suggested an innovative finger knitting-based system to train university students who studied knitwear design. This method aimed at filling up the linkage between fundamental knowledge and realistic application of knitting. It integrated well-balanced art, technology and service-learning to meet the market needs. Comprehensive guide explaining its principles and research on the effectiveness of this method would be discussed.

\section{Finger Knitting-Based Education System}

Fundamental knitwear design subject was recommended to employ this novel teaching method. Students were required to learn the knitting principles and techniques by finger knitting. Both weft and wrap knitting, flat and circular knitting methods can be exemplified by finger knitting methods. Finger knitting could also perform almost all knitted patterns and structures, like such as jersey, cable, jacquard, floating, tuck and missing stitch. This thus provides a simple yet effective way to help students to have better understanding of knitting technology. Below are the brief introduction and demonstration of finger knitting and its techniques (Figure 2).

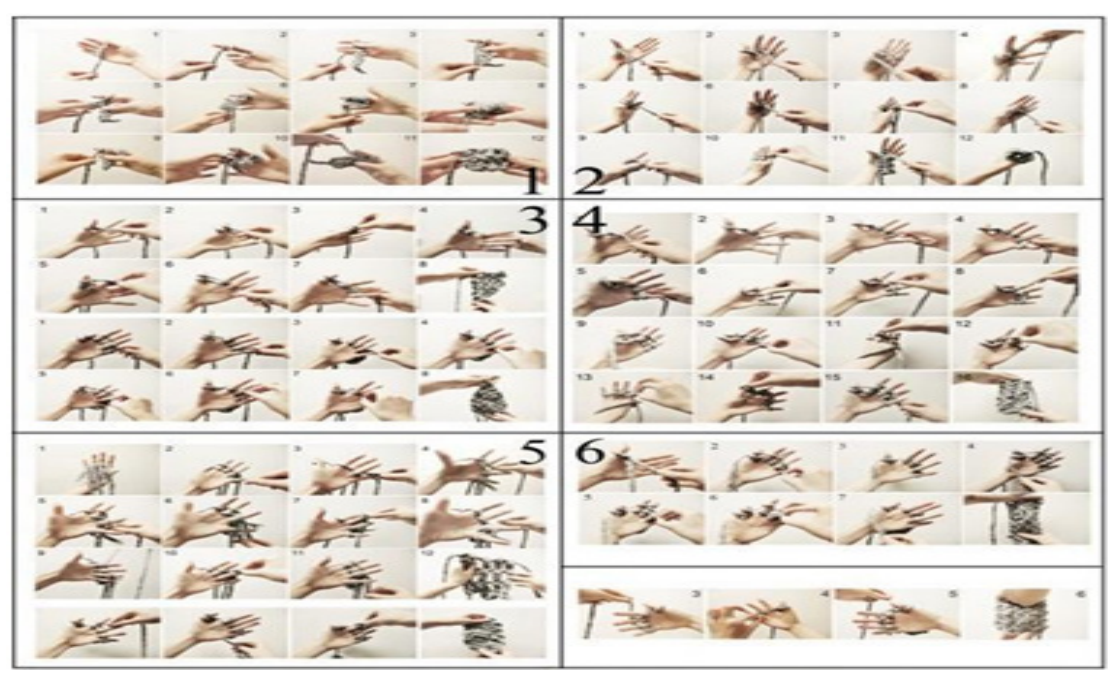

Figure 2: Illustrations of the use of fingers to produce various knitting stitches: 1) crochet stitch; 2) circular knitting stitch; 3) increasing loop and decreasing loop; 4) rib stitch (V-bed flat machine); 5) warp knitting and float stitch; 6) tuck stitch and jersey stitch. 
The teaching and learning of knitwear design by finger knitting-based system involved essential textile fabrication steps as usual. For example, it included materials selection, yarns design, size measurement, and knitting design and so on. Underwent those processes enabled students to familiar with real knitting industry practices. The materials selection processes required students to understand the yarns properties and predominate the yarns design skills. In addition, finger Knitting imitated the technique of machine knitting. Hands replaced the knitting bed while fingers replaced the needles, such as latches, to complete the knitting processes. The movements of the fingers demonstrated the loop formation steps, included clearing the old loop, feeding the yarn and knocking-over.

The distance between fingers imitated the machine gauge to control the density. The knit pieces were also having similar characteristics of traditional machine knitted fabric, such as edge curling. With real-time finger knitting demonstration and practice, students could link up the theoretical principles and machine manipulation (Figure 3). Students were expected to attend a series of small group lectures and tutorials focused on providing them a critical understanding of knitting principles by finger knitting methods and offering them with practical training on finger knitting and machine knitting. It hoped that the relationship between finger knitting and machine knitting could demonstrate the complicated yet essential knitting theory in a simple way step by step. For one semester learning and teaching, students had to imitate the whole process in knitting industry, including yarn design, pattern making, garment design and production and finishing. Eventually, students had to submit a knitted garment that involved these processes. Hence, students were not just grasping the knowledge of knitting techniques, but also the procedures in knitting industry. As a result, this enhanced their learning and facilitated their future employment in industry.
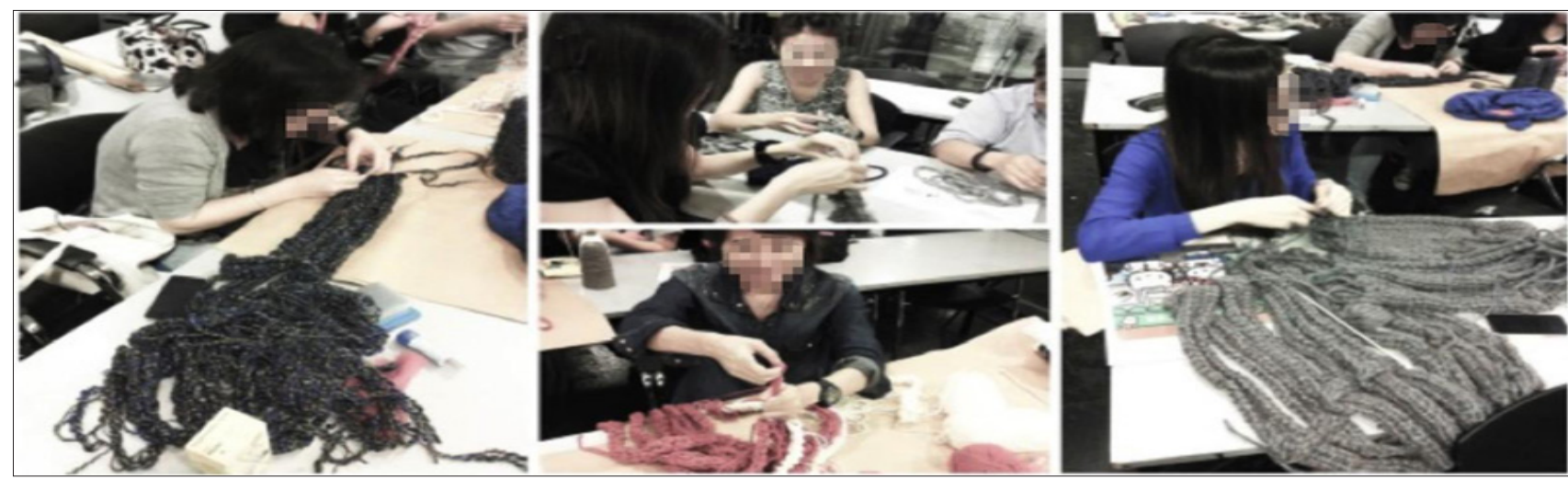

Figure 3: Photos of students performing finger knitting during the tutorials.

It also hoped that students could involve in a service learning session that they organized and shared their finger knitting with others. Finger knitting was also an effective means of improving hand functions and muscle strengths as simple hands and fingers' functions were needed. It was especially good for elderly service to tackle with recent ageing and health problems in the society. Students were thus required to plan and organize the workshops for their group's target. During their community service, reflective seminars could be organized to provide opportunity for students to share their service experiences with other students and supervisors, and discuss their learning and serving strategies and techniques in order to successfully apply their knowledge to support community service. This, hence, helped to link their academic content of subject with the service learning activities and deepened their understanding on their learning at university (Figure 4).

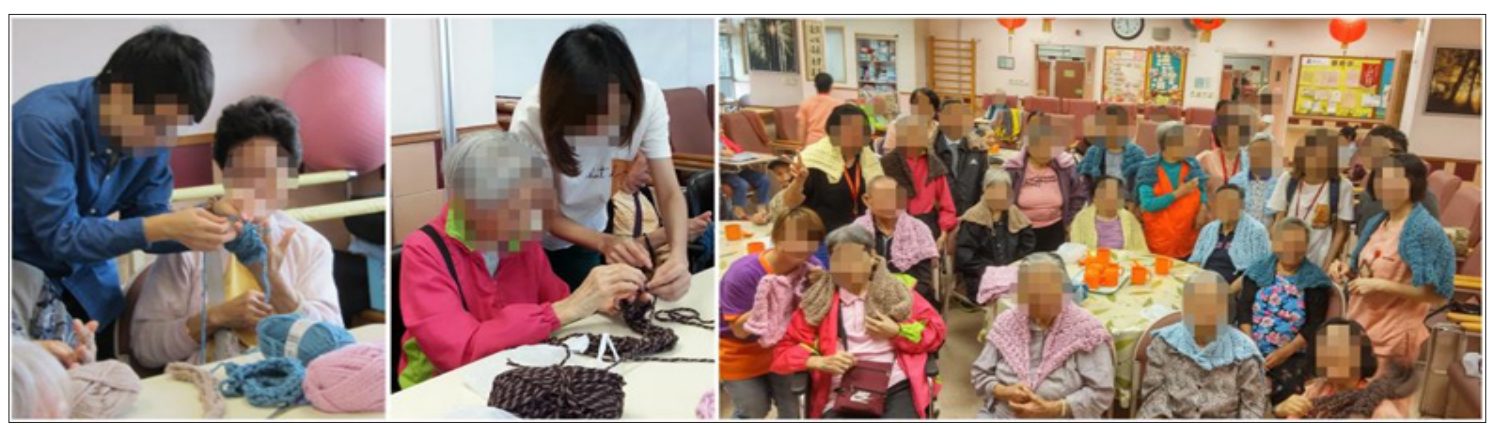

Figure 4: Activities photos of sharing finger knitting in the community (elderly centre).

\section{The Study}

To understand and investigate the effectiveness of this method, pilot study was done. The study took "knitwear design" subject of university as the pilot subject to employ the new teaching method. This teaching and learning method had employed for 6 years in the university subjects of knitwear design. All students were from 
fashion and textile study. More than 300 of students enrolled in the past years. To investigate the effectiveness and acceptance of this finger knitting-based education method, student feedback questionnaire developed by the university was adopted. Also, informal interviews and observations were the major methods to investigate the acceptance of students and the effectiveness of this method (Figure 5). For one semester learning and teaching, students had to imitate the whole process in knitting industry, including yarn design, pattern making, garment design and production and finishing. Finally, they were encouraged to bring their learning into community to share the finger knitting techniques (Figure 6).
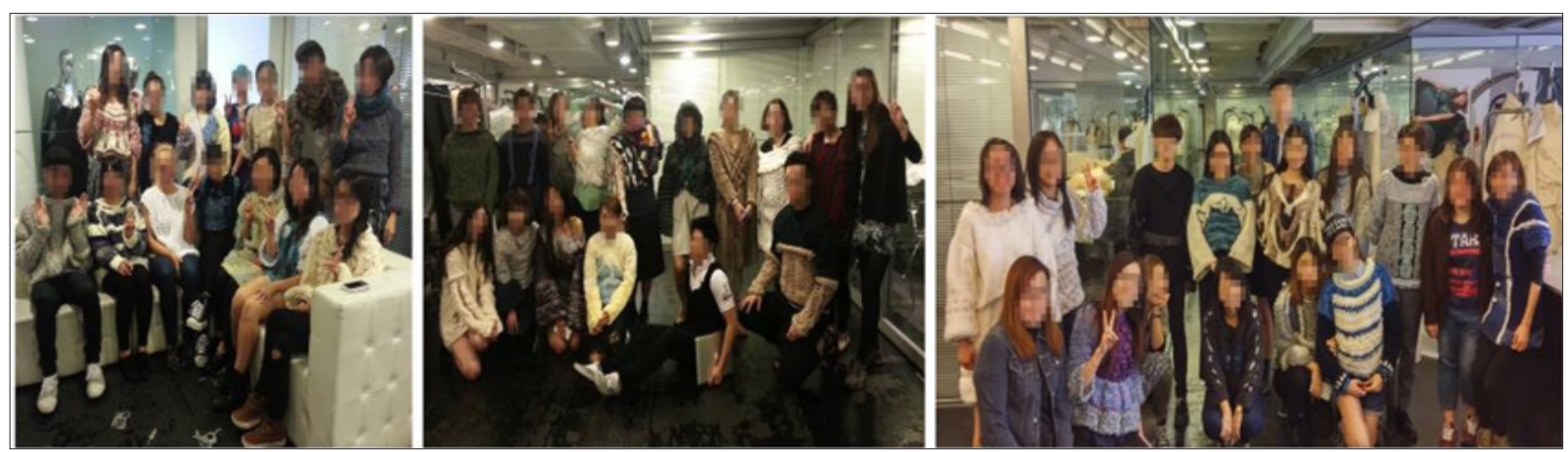

Figure 5: Photos of students wearing their own finger knitted garment.

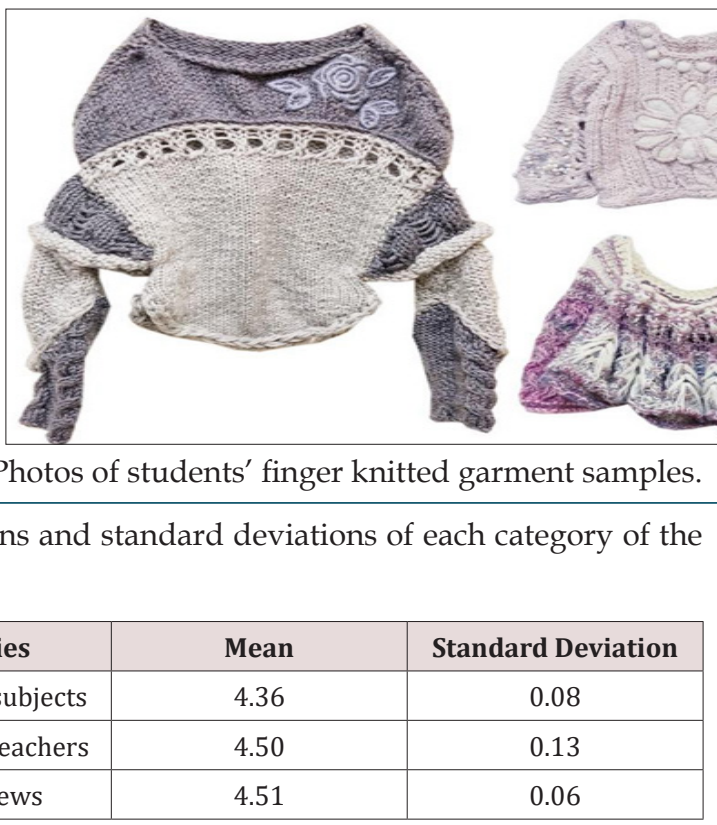

From the student feedback questionnaire, it used 5-point scale to test the level of agreement of the sentences. It asked questions regarding the comments of the subjects and the views of the teachers. For instance, a sentence concerning the opinions on the subject was "teaching and learning activities helped me to achieve the subject learning outcomes". There were totally 4 questions regarding the views on subjects, 5 questions regarding the teachers and 2 questions regarding the overall views. 128 students completed the form. The mean scores of the past years were more than 4.5 , which were significantly higher than the faculty mean of 3.9 and placed among the top $10 \%$ of the institution. This clearly showed that the teaching and learning method was highly accepted and appreciated by students. Table 1 shows the means and standard deviations of each category of questions(table 1).

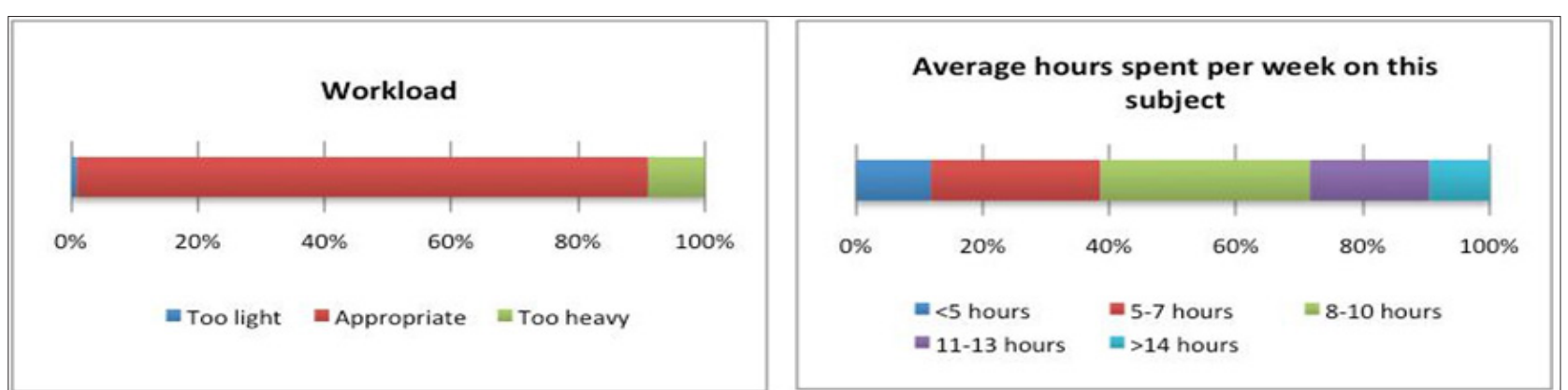

Figure 7: Figures showing students' opinions on the workload (left) and; their average time spent per week on this subject (right). 
There were also questions concerning about the workload and average hours that students spent per week on this subject in order to understand the level of suitability of course setting. The results were shown on Figure 7. More than $90 \%$ of students thought that the workload and assignments were appropriate. Majority of students spent around 8-10 hours per week, followed by 5-7 hours. The time included the lectures, tutorials, workshop and other related works done. Hence, the workloads were acceptable by students (Figure 7).

From the informal interviews and observation, all of the students felt satisfied with the subject teaching method and found it useful to understand the principles of knitting and linked up with their laboratory learning's. Below was the discussion concerning their opinions and this responded to objectives of the finger knitting-based education system by thematic analysis? The main themes were threefold:
a) Learning and personal growth
b) Creativity and empowerment
c) Enjoyment.

\section{Learning and personal growth}

During the finger knitting learning process, all students found it easy-to-learn yet useful. Students knew neither knitting nor finger knitting before and only a few of them know hand knitting. They learned it during the lessons and found that it was amazing. Only some of them needed to repeat the steps and tries more times to grasp the skills. However, all of them were able the grasp the basic techniques at the end of the first practicing lesson. With demonstration and practicing activities, they were able to integrate the theory with the practical skills.

"It is a bit challenging at first. I need to pay attention and follow the steps carefully. But after I grasp the basic techniques, I find it very interesting to change a little step to create new patterns... I also can understand the principles of knitting easily and able to apply it on the laboratory lesson (where machine knitting was employed)."

"With the practice of finger knitting, I understand the importance and underlying principles of machine gauge and yarn tension. Before, I just memorized the calculation formula of them."

"Making the knit garment by hand (finger knitting) really helped me understand the structure of knit garments and how machines work."

"The way that how the knitting needles move up and down and the setting of needles, all can be learned from using my fingers to knit garment easily"

"I learned the teaching skill of knitting, the real situation of the industry and how to do the work of knitwear designer."

Apart from better understanding of the principles and grasping of machine knitting, more examples regarding the benefits of finger knitting as a teaching method could be found. Since students found it "amazing", they were curious about the techniques and the effects on the knit pieces. Some of them would ask questions concerning about finger knitting. This active questioning situation was seldom appeared with traditional teaching methods on Chinese classroom. Take edge curling as an example. After finger knitting a knit piece, edge curling would happen as usual. Students would then ask for the reasons why this situation would occur and how to avoid it. Also, many of them even tried to apply it for creating new patterns and made their own pieces afterwards. These showed an encouragement of active classroom.

"The most useful to my learning is that the principles of knitting and different styles of knitting... at least I can knit something in the future even I don't have a needle. But we do finger knitting."

"Different stitch can be learned and understood easily by finger knit... it will be great if more stitches can be taught in class."

As students were required to accomplish a knit garment by finger knitting as their final assignment, they needed to do all the planning and preparation, such as yarn selection, time control, measurement, costs calculation and design. This was not just enabled them to undergo the whole production process of a knit garment, but also help to improve their ability of management and thus facilitated personal growth.

"A very all-rounded syllabus."

"Interesting. I need to find suitable yarn and choose suitable knitting construction to match my theme. Next time, I may try to create yarn as well."

"After I finished my assignment, I found that it is not easy to make a knit garment. It involved so many procedures and required plenty of planning... It is a good learning process for me. I learned problem-solving skill and became more patient."

Furthermore, with the experience of sharing their skills with others and brought it into social setting, students could link their academic content of subject with the service learning activities and deepened their understanding on their learning at university. They also could have better understanding towards the community and thus might devote themselves in community service and balanced their academic study with social servicing activities. This, eventually, might facilitate positive growth.

\section{Creativity and empowerment}

The creative power was unquestionable that students were able to create a piece of their own knit garment successfully. This also brought them a sense of achievement and empowered them to create their own piece and express their views via knitwear design. All of them were able to transform their idea into a well-finished knit garment. During the process, they had to make the knitgarment stepby-step. Through these, they were able to understand themselves more. They knew more about their strength and weakness and this 
helped in facilitating positive change. For instance, when they chose to knit a pattern or structure, they had to understand the knitting principles and apply the skills flexibly to achieve it, especially if the pattern or structure was not conventional one. This improved their creative thinking and problem-solving skills.

"It is a bit challenging at first. I need to pay attention and follow the steps carefully. But after I grasp the basic techniques, I find it very interesting to change a little step to create new patterns."

"I knew more knitting skills and changed my mind to knit."

"Finger knitting is a skill that can be well used in fashion design."

"Finger knitting is very useful and has good effect."

Another obvious empowerment observed was that students were able to share their skills and thoughts. As a major activity in class, students learned and shared new skills together. They could ask for help when they had problems. On the other side, they taught others, either in class or in social setting. This might help to build up sense of belongings and self-confidence, which involved numerous benefits.

\section{Enjoyment}

Noticeably, many students found that finger knitting brought "enjoyment" and "satisfaction" to them. They thought it was interesting and unique.

"I never knit or crochet before. I think it is fun, cute and enjoyable."

"Machine knitting is convenient but finger knitting bring satisfaction."

"Finger knitting is very interesting for me. It is a fanny experience."

Students also felt satisfaction due to the sense of achievement obtained. They were all able to accomplish a knit garment and most of them were wearable and even marketable. In addition, they felt relaxed and happy when compared with other subjects. Some of them thought it even helped to alleviate their stress.

"When I feel stressful with studying, I try to do something else as a break... A bit surprise that after a half hour knitting, I free from the nervous feeling of my studying and concentrate on knitting. Although I still feel pressure from the exam, I am more relax and happier."

Another major reason of enjoying the finger knitting-based teaching and learning method might relate to the peer support and active classroom learning. Learning was through activities and active participation instead of passive and memorizing methods. Apart from this, it was generally believed that helping and serving others is the foundation of happiness. Service learning and sharing skills might enable students to be happier. Also, through this, people in the community might find that students do care the community and helped to bring the community closer and closer.

\section{Conclusion}

In the light of the prolonged history of knitting, it was traditionally regarded as an insignificant subject in current curriculum. Even through knitting was undergoing revival and regained popularity, there was lacked of systematically education method to integrate knitwear design, knitting technology and service learning. The case was even more serious in Chinese culture as passive learning style was prevalent. Hence, this study suggested an innovative finger knitting-based education method for knitwear design. It linked the fundamental knowledge, realistic application and service setting of knitting. It hoped to provide a systematic and professional training to future knitwear designer.

Finger knitting imitated machine knitting. It helped to demonstrate weft knit, wrap knit, flat knitting and circular knitting. Finger knitting could perform almost all knitted patterns and structures. Yet, it was easy-to-learn and could help students to understand the underlying principles of knitting. It also would not limit students' creativity and enabled them to create their own garment freely. Moreover, knitting was usually regarded as a good way for social service. This also enabled the service learning. Students could apply their academic learning in social setting. Hence, this could deepen their knowledge understanding and arouse their awareness towards society.

In order to study its effectiveness and acceptance, survey, informal interviews and observation were employed. Students were very satisfied with this teaching and learning method. Thematic analysis showed their major themes regarding their perceptions and thoughts were

a. Learning and personal growth

b. Creativity and empowerment

c. Enjoyment.

To sum up, it was clear that finger knitting-based education method might be a good solution for current knitwear education dilemma. More study should be done to validate its effectiveness. For example, in future study, students' demographic background might take into consideration since art background students might weaker in science than technological background students, vice versa. Nevertheless, finger knitting was still worth for future investigation due to its advantages showed in this study.

\section{References}

1. Gastonia NC (2012) Passionate Consumers Pass It On! Craft Yarn Council.

2. Lewis $P$ (2011) Pride in the wool: the rise of knitting. The guardian, UK.

3. Riley J, Corkhill B, Morris C (2013) The benefits of knitting for personal and social wellbeing in adulthood: findings from an international survey. The British Journal of Occupational Therapy, 76(2): 50-57. 
4. Scarmeas N, Levy G, Tang MX, Manly J, Stern Y (2001) Influence of leisure activity on the incidence of Alzheimer's disease. Neurology 57(12): 2236-2242

5. Valenzuela MJ, Matthews FE, Brayne C, Ince P, Halliday G, et al. (2012) Multiple biological pathways link cognitive lifestyle to protection from dementia. Biological psychiatry 71(9): 783-791.

6. Jones H (2012) Knitting and Dementia Sufferers. In Therapeutic Knitting Stiudy Day - Knitting to Facilitate Change. Stitchlinks CIC.

7. Abbott B (2009) Knitting-It's the new yoga. Express, UK.

8. Joy K (2009) A craft revolution: New generation of do-it-yourselves churns our goods. The Columbus Dispatch.

9. Derringer J (2013) She's crafty: yarn bombing pioneer Magda Sayeg. Design Milk.

10. Theaker J (2006) History 101.

11. McIntosh P (2011) Knitting: A Craft Makes a Comeback. In English Teaching Forum. ERIC, US Department of State 49(1): 36-43.

12. (2014) The UK Hand Knitting Association. Knitting Statistics, UK

13. Davila F (2005) Here's a good yarn: Knitting fans keep eye on the ball. Seattle Times, Local News, USA.

14. Wills K (2007) The close-knit circle: American knitters today. Greenwood Publishing Group, USA.

15. Knit the City (2015).

16. Pentney BA (2008) Feminism, Activism, and Knitting: Are the Fibre Arts a Viable Mode for Feminist Political Action? thirdspace: a journal of feminist theory \& culture $8(1)$

17. Minahan S, Cox JW (2007) Stitch'nBitch Cyberfeminism, a Third Place and the New Materiality. Journal of material culture 12(1): 5-21.
18. Magiconlie (2015) Millennials Running Up Hosiery Sales. Magiconline, UK.

19. Ma A, Pendergast D (2011) The past, the present and the preferred future for home economics education in Hong Kong. International Journal of Consumer Studies 35(5): 589-594.

20. Cheung FM (1989) The women's center: A community approach to feminism in Hong Kong. American Journal of Community Psychology 17(1): 99-107.

21. McGregor SL, Pendergast D, Seniuk E, Eghan F, Engberg L (2008) Choosing our future: Ideologies matter in the home economics profession. International Journal of Home Economics 1(1): 43.

22. Kennedy P (2002) Learning cultures and learning styles: Mythunderstandings about adult (Hong Kong) Chinese learners. International journal of lifelong education 21(5): 430-445.

23. Findeli A (2001) Rethinking design education for the 21st century: Theoretical, methodological, and ethical discussion. Design issues 17(1): 5-17.

24. Astin AW, Vogelgesang LJ, Ikeda EK, Yee JA (2000) How service learning affects students. Higher Education Research Institute, University of California, USA

25. Bringle RG, Hatcher JA (1996) Implementing service learning in higher education. The Journal of Higher Education 67(2): 221-239.

26. Furco A (1996) Service-learning: A balanced approach to experiential education. Introduction to service learning Toolkit. Chicago, USA.

27. Kolb DA (2014) Experiential learning: Experience as the source of learning and development. FT press, USA.

28. Demirbas 00, Demirkan H (2007) Learning styles of design students and the relationship of academic performance and gender in design education. Learning and Instruction 17(3): 345-359.

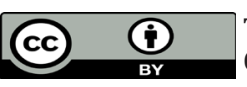

This work is licensed under Creative Commons Attribution 4.0 License

Submission Link:

$$
\text { Submit Article }
$$

DOI: 10.32474/LTTFD.2018.01.000115

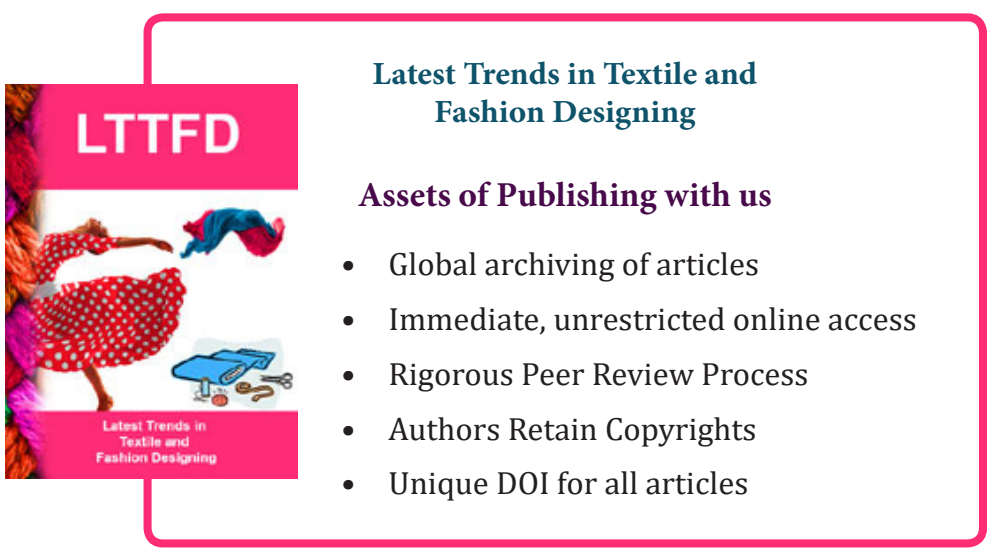

